\title{
Effective Implementation of Green Computing
}

\author{
Navdeep Kaur \\ Guru Kashi University, \\ Talwandi Sabo, \\ Punjab, India.
}

\author{
Pardeep Mittal \\ Guru Kashi University, \\ Talwandi Sabo, \\ Punjab, India.
}

\begin{abstract}
A safe and non-polluted environment is the basic need of a living being. But today the situation is getting changed. Our environment is getting polluted day by day at a very high rate. The use of computing devices plays a vital role in harmfulness of environment. To reduce these harmful impacts the concept of Green Computing must be implemented. In this research paper we count some factors and find some issues and challenges which are barrier towards implementation of green computing. The main reason the awareness of a common user. If a common user is getting aware about the harmful impacts of use of computing devices over environment and takes some steps at own level to reduce electricity, the concept of green computing will be implemented.
\end{abstract}

Keywords: Energy Star, Blackle, TCO, ICT, $\mathrm{CO}_{2}$ Emission.

\section{INTRODUCTION}

Green computing is the study and practice of designing, manufacturing, using and disposing of computers, servers, associated, subsystems such as monitors, printers, storage devices, and networking and communication systems efficiently and effectively with minimal or no impact on environment. The concept Green computing is come into existence in 1992 when the U.S environmental protection agency launched energy star, energy star is voluntary labeling and recognize energy efficiency in monitors, climate control equipment and other technologies. The goal of green computing are power management and energy efficiency choice of eco-friendly hardware and efficient software and material recycling and increasing the product's life. With the help of ICT (Information and Communication Technology), Green computing become an effective approach to grow segments that affects carbon emission. It also implements Energy Star management strategies and technologies that reduced energy consumption waste. Today computing devices are the basic need of human. These devices make our life easy as they save a lot of time and human efforts. The benefits of computing device are known to everyone but no one is aware about the harmful impacts of computing devices on environment. The main reason behind it is the less awareness about the harmful impacts of the use of computing devices. I take a little initiative to aware the common man about the term Green Computing, its benefits and how the Green Computing is implemented.

\section{OBJECTIVES OF STUDY}

The main objectives of the study are:

1. To aware the common man about term green computing.

2. To reduce energy consumption \& protect the environment.

3. To find the difficulties occur in implementation of green computing.

4. To aware the common man about the efforts need to done by them for green computing.
5. To aware the common man about the organizations who take initiatives to promote green computing.

6. To make the people aware about the role of government to promote green computing.

\section{RESEARCH METHODOLOGY}

For implementation of green computing we have to go through various issues and challenges occur in implementation of green computing. After a thorough study of these issues and challenges we choose various factor variables. These factor variables are further categorized into various categories and a questionnaire is prepared from these factor variables. Questionnaire is distributed among 220 people and collected their responses. We prepare results from these responses using statistical tools and represent these results with the help of graph. After preparing graph conclusions are draw using data mining tools.

\section{CATEGORY FACTOR VARIABLES:}

V1. Do you ever use any computing device?

V2. Which type of computing device are you using?
2.1. Laptop
2.2. Desktop
2.3. Mobile
2.4. Net book
2.5. Any other please mention

V3. Are you familiar with term operating system?

(If yes, check the following, if no skip this question)

3.1. Which operating system have you ever used?
3.1.1. Linux
3.1.2. Unix
3.1.3. Windows
3.1.4. DOS
3.1.5. Mac
3.1.6. Any other please mention

V4. Which type of processor do you use? 

1.1. Intel
1.2. AMD
1.3. VIA
1.4. Don't know

V5. Which search engine do you use?

5.1. Google

5.2. Yahoo

5.3. Blackle

5.4. Bing

5.5. Any other please mention

V6. Do you ever use printer?

(If yes than please check the following)

6.1. Which type of printer do you usually used?

6.1.1. Inkjet

6.1.2. DeskJet

6.1.3. Laser Jet

6.1.4. Any other please mention

V7. Awareness about environment.

7.1. Do you really care about environment?

7.2. Do you know that the use of computing devices put harmful impacts on our environment?

7.3. Do you know about term $\mathrm{CO}_{2}$ emission?

7.4. Do you know most of the $\mathrm{CO}_{2}$ emission is generated through computers and its devices?

7.5. Do you know the high consumption of electricity also plays a big role towards harmful environment?

7.6. Do you know most of the parts of computers are not biodegradable?

7.7. Do you know there are many toxic chemicals are used while manufacturing of computer?

7.8. Do you know about world environment day?

7.9. Do you know world environment day is celebrated on $5^{\text {th }}$ June of every year?

7.10. Do you know world environment day is celebrated to raise global awareness to take positive environmental action?

7.11. Do you know world environment day is going to complete his 41 year on $5^{\text {th }}$ June $(1973-2013)$ ?

7.12. Do you know every year a new theme related to environment is taken for world environment day to save our environment?

7.13. Do you know in last 41 years (1973-2013) term green computing is not become the theme of world environment day?

V8. Awareness about Green Computing, (please attempt if already known)

8.1. Familiar with term Green Computing.

8.2. Green Computing is also refer to environmentally sustainable computing.
8.3. The goal of green computing is to reduce the hazardous material and save our environment.

V9. Energy star program - please check if already familiar

9.1. Energy Star is an international standard for energy efficient consumer products.

9.2. Energy star launched in 1992 by Environmental Protection Agency and the Department of Energy.

V10. Are you know about TCO Development, (Please check if already known)

10.1. TCO development is the sustainably certification for IT products.

10.2. It works to ensure that the manufacturing and recycling of IT products are carried out with regards to environment.

10.3. TCO development is headquartered in Stockholm, Sweden, with regional presence in USA and Asia.

10.4. TCO development introduced TCO certificate for sustainability certification of IT products

10.5. TCO certificate was associated with computer monitors but later TCO revision also defines standards for computers, keyboards, printers, mobile phones and office furniture.

V11. How much you aware about recycling and disposing, (please check if already familiar)

11.1. Familiar with disposing of computing devices

11.2. Familiar with recycling of computing devices

11.3. Familiar with formal and informal disposing

11.4. Informal disposing is harmful to our environment

11.5. Formal disposing is costly but sustainable to our environment.

V12. How much you aware about manufacturer's initiatives towards green computing - are you ever know?

12.1. Dell purchasing $129 \%$ of its conventional usages in green power

12.2. Dell's latitude E-Series laptops and the OptiPlex desktops are designed for energy efficiency

12.3. HP's eco solution program provides inventive, High quality products and services that are environmentally sound

12.4. Intel's core i3, i5, and i7 processors minimize the amount of unnecessary power that get used

12.5. These CPU's are small in size and made of high $+\mathrm{k}+$ transistor technology that doesn't over leak electricity.

12.6. Wipro's green testing lab at Sarjapur campus that test products to conforms that they are "green" complies 
12.7. Wipro's e-waste disposal service, Eco friendly product engineering design and green data centres are steps towards green computing.

V13 How much effort you are taking towards green computing?

13.1. Do you have more than one computer?

13.2. Are you using computer from a long time?

13.3. Are you using computer more than 5 hour per day?

13.4. Do you turn off your computer when it is not in use?

13.5. When you purchase new electronic device do you consider energy star logo?

13.6. Have you any product with energy star logo?

13.7. Are you doing efforts to saving energy at home?

13.8. Do you always consider about cost while purchasing product?

13.9. Have you seen or heard about any campaign about green computing?

13.10. Have you ever disposed any computing device?

13.11. Do you use screensavers on your computer?

13.12. Does screen saver save energy when computer is idle?

13.13. Do you know Google's Blackle search engine is less energy consuming search engine?

13.14. Do you ever use Google's blackle search engine?

13.15. Are you printing more than 20 pages daily?

13.16. Is cartridge refilling greener than replacing it?

13.17. Can you save a lot of money by Green Computing?
14.1. Should government reserve some money for green computing in budget?

14.2. Should government have to promote green computing?

14.3. Should government have to promote formal disposing?

14.4. Should government have to give subsidy for formal disposing?

14.5. Should government take steps to aware people about green computing?

V15. The objectives of my research - are you agree or not?

15.1. Every common man should have to aware about green computing and its benefits

15.2. Government should have to take strict actions to implement green computing

15.3. Computer manufacturers should has to manufacture less energy consuming and less heat generating devices

15.4. Every computer user must turn off their computer if it is not in use for more than 3 minutes

15.5. Various NGO's should also have to take serious actions to save our environment not only from other pollutions but also from the pollutions that is generated through the use of computer and its devices

15.6. Time to time campaign should have been conducted to aware a common man with green computing

15.7. Universities and colleges should have to aware their students about green computing

15.8. Green Computing should also have to be teaching as a regular subject in every university and college.

V14. Role of government towards green computing

\section{ANALYSIS AND INTERPRETATION (USING DATA GRAPHS)}

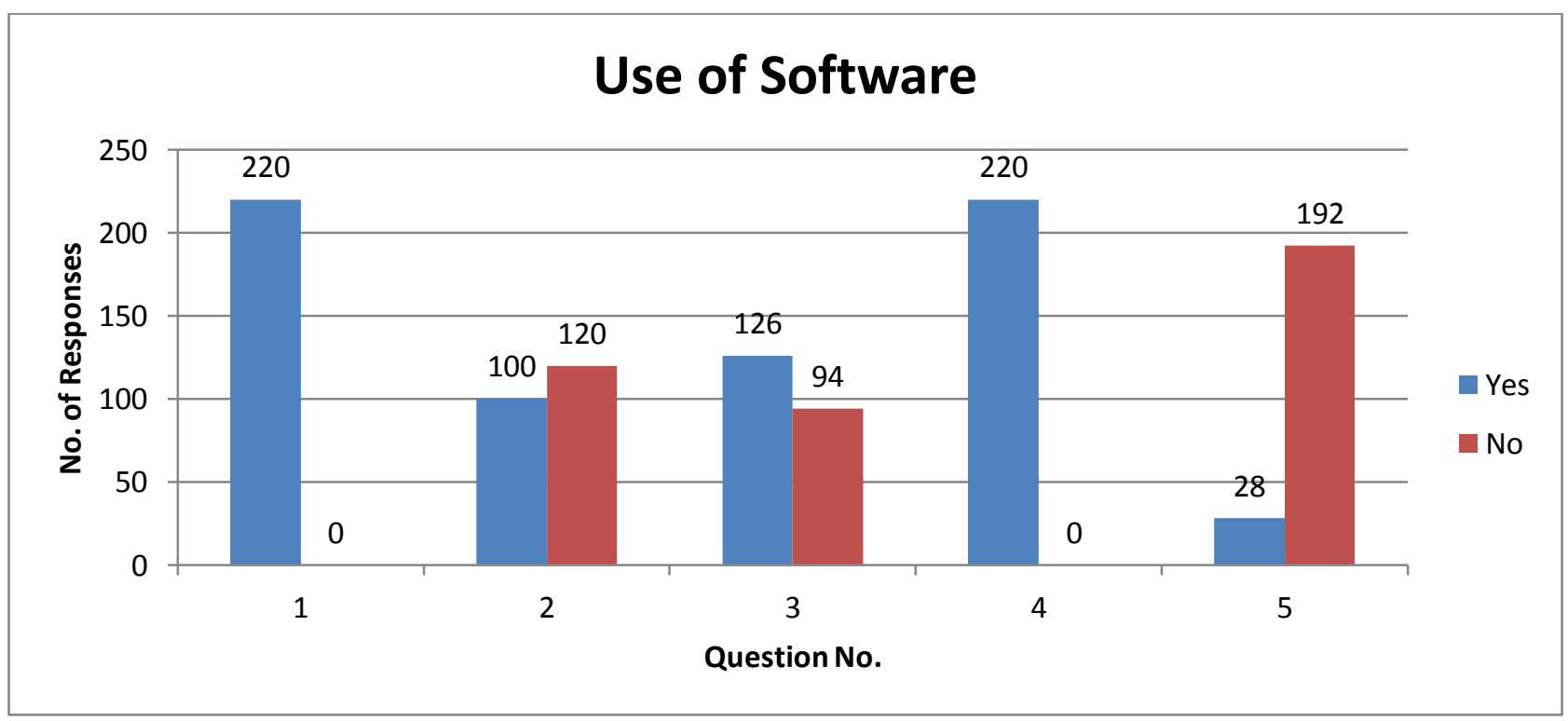



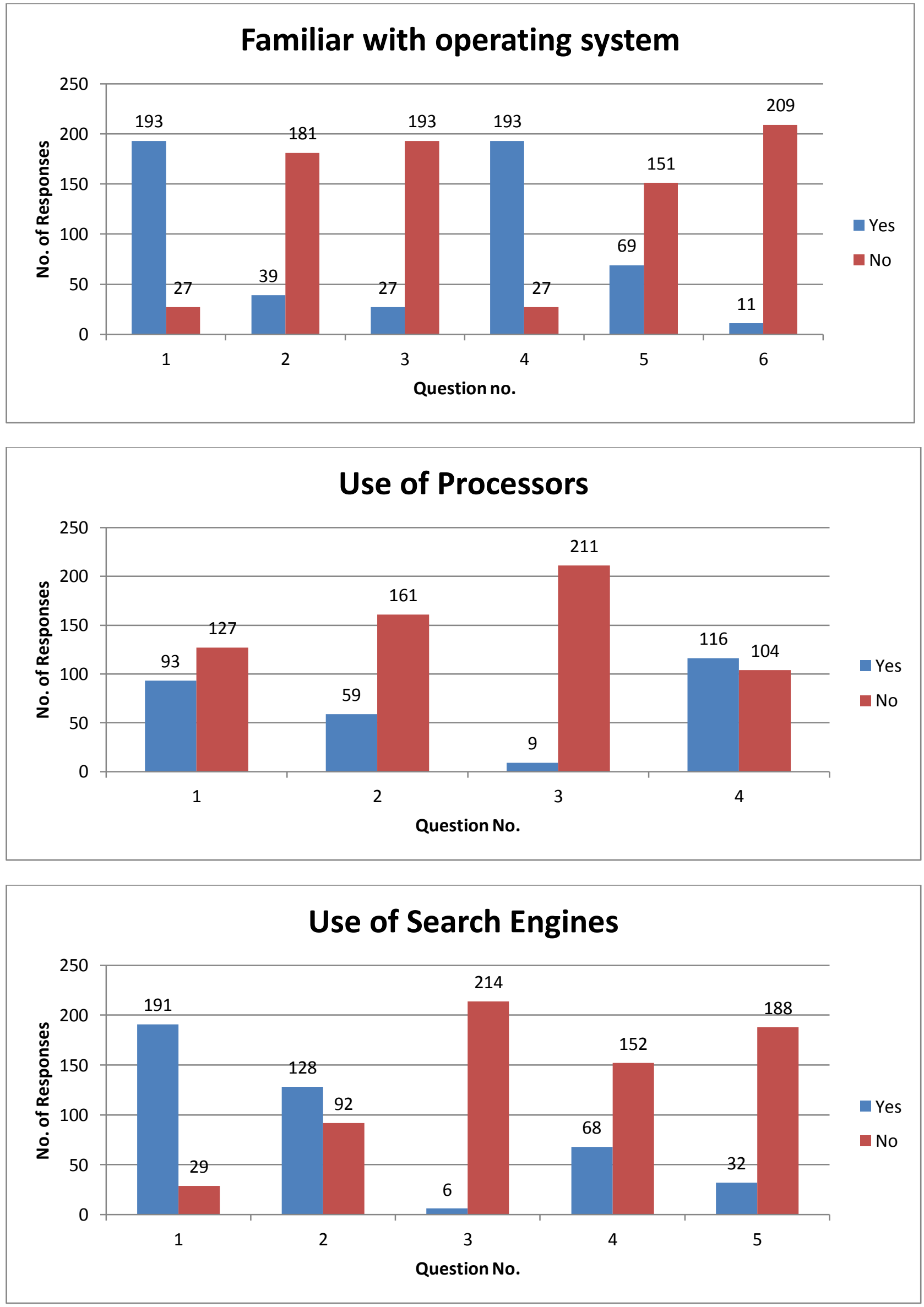

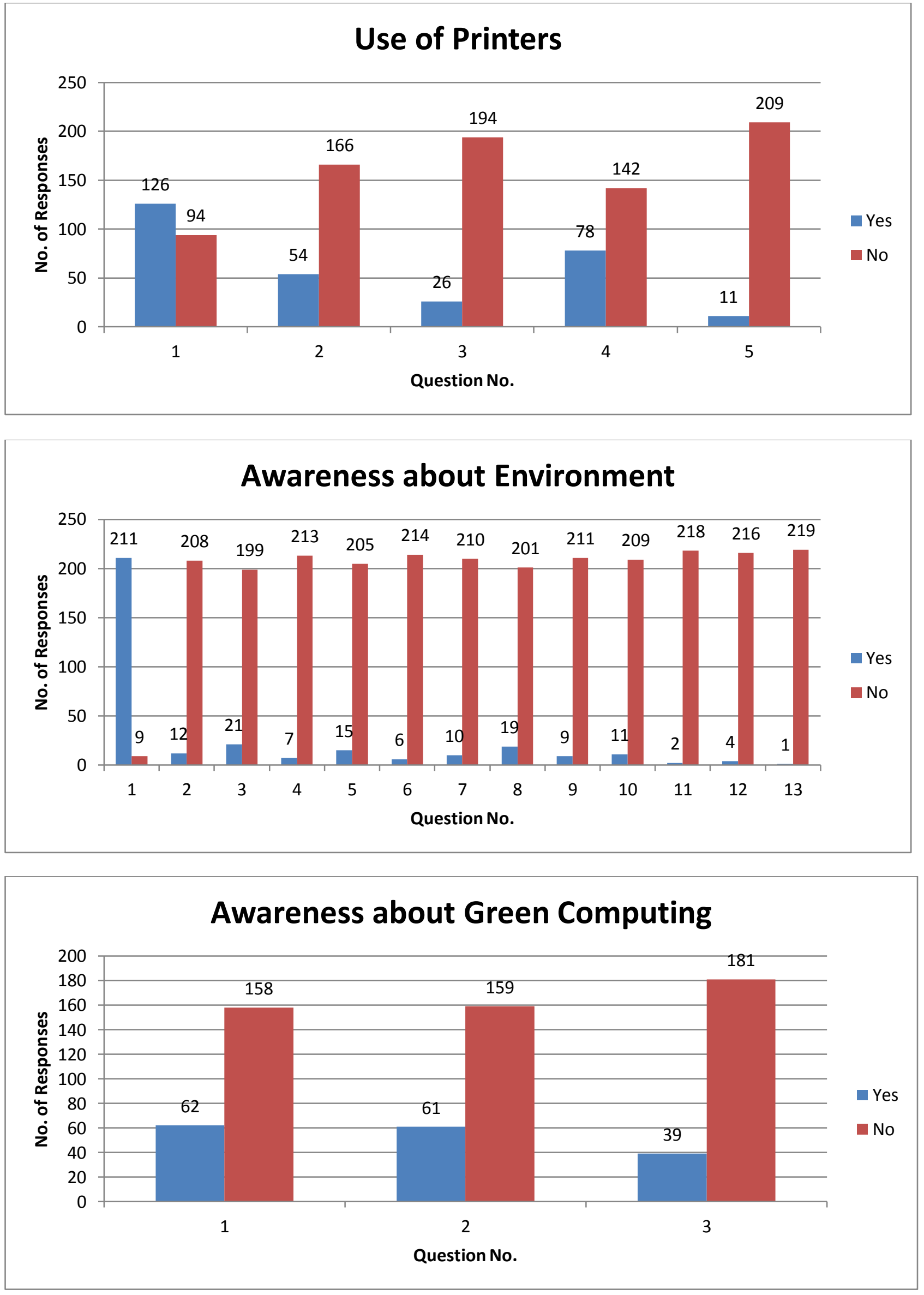

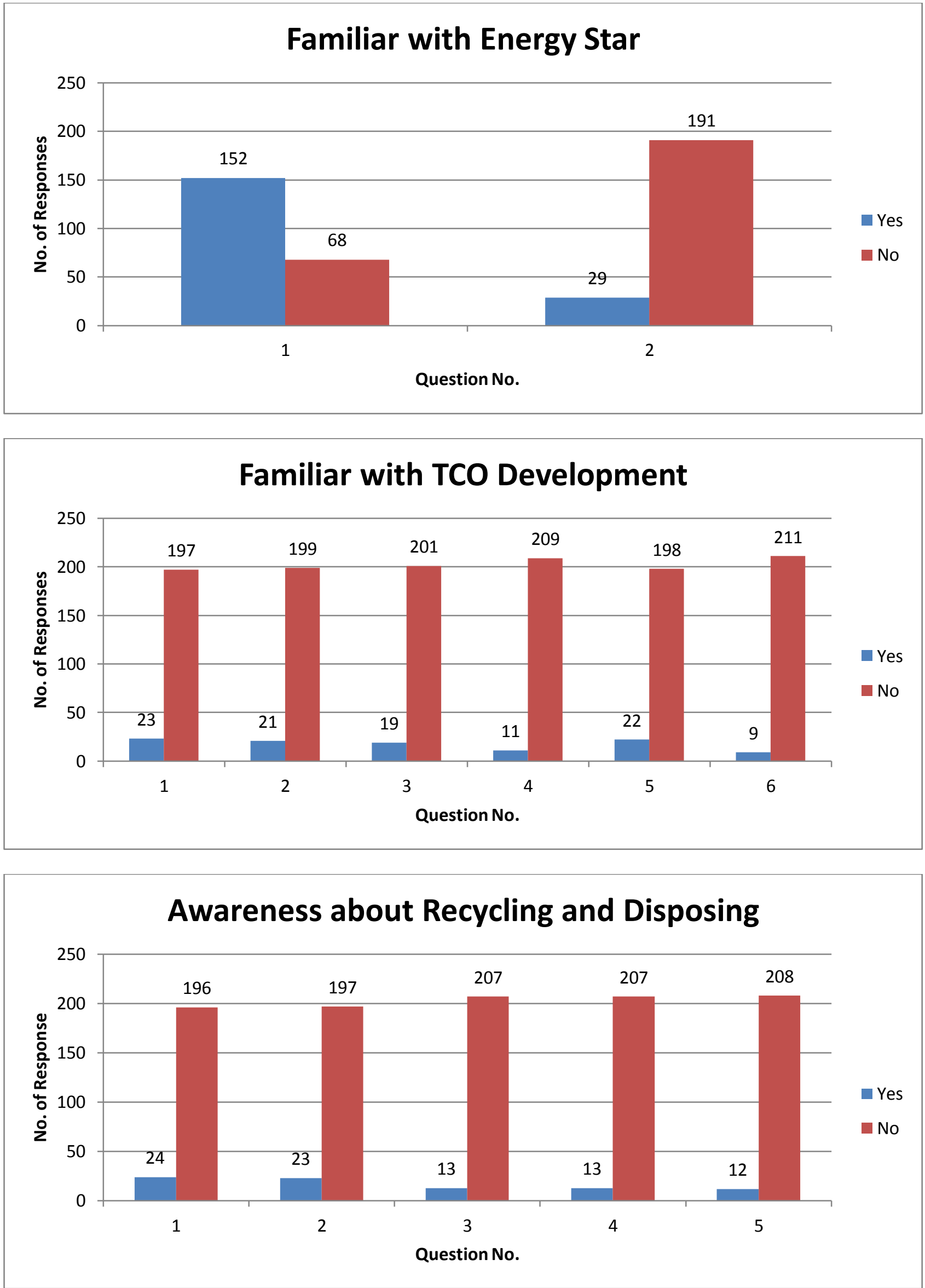

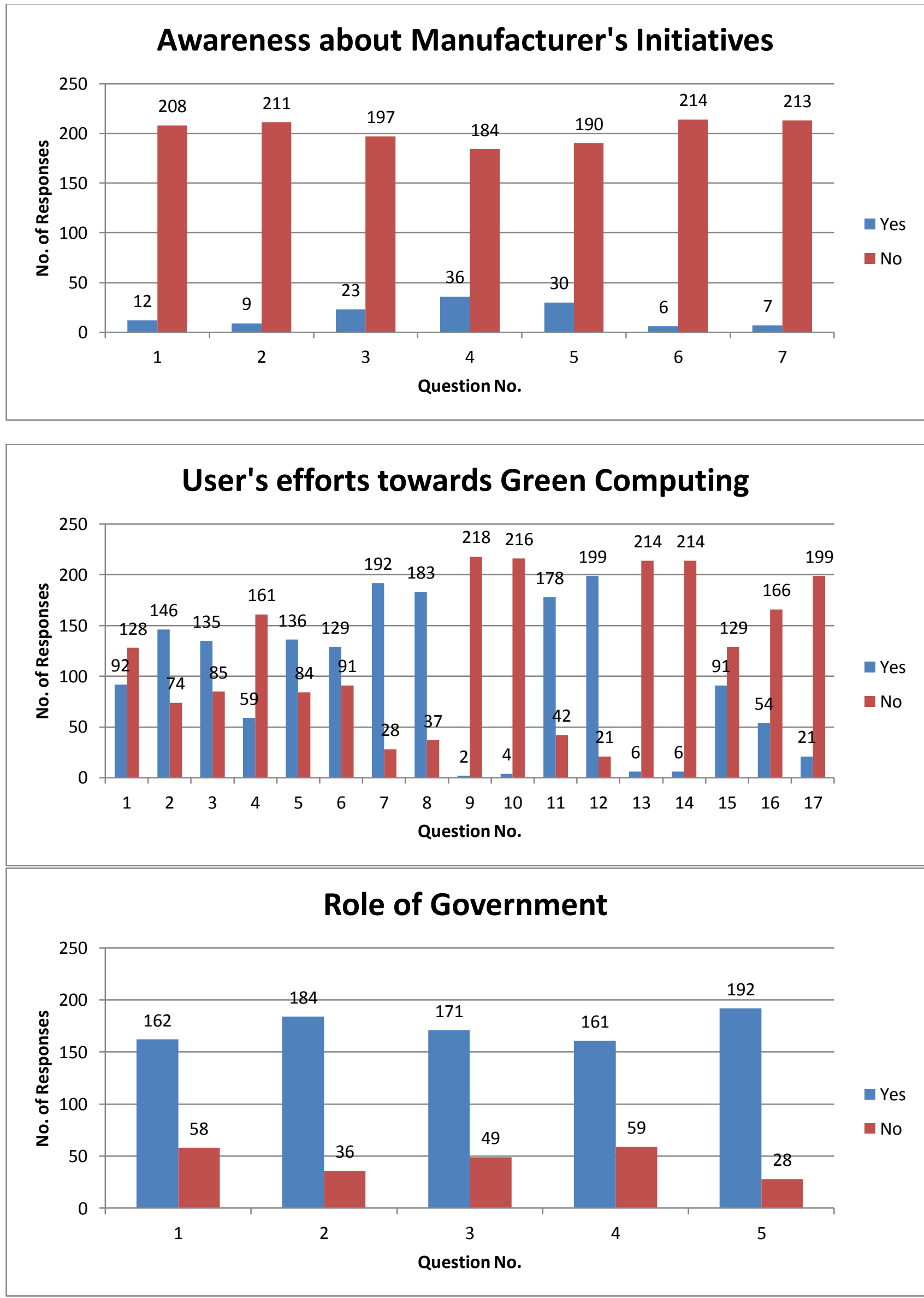


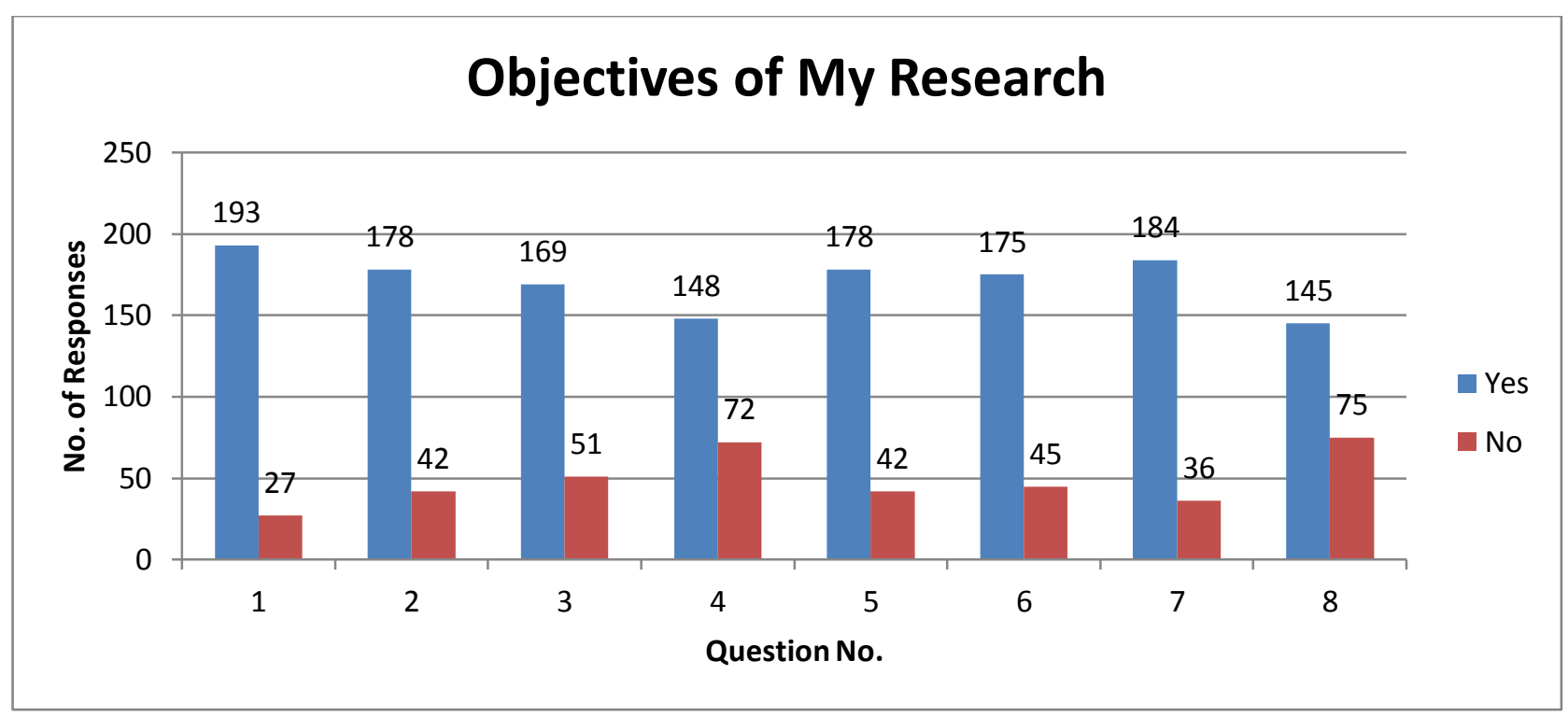

\section{CONCLUSION}

1. According to my survey report $100 \%$ people are using computing devices in which almost everyone using mobile phones, $45 \%$ use laptop and $57 \%$ use desktops.

2. $87 \%$ people are familiar with term operating system, all these $87 \%$ people are familiar with windows operating system but only $17 \%$ are familiar with Linux and only $5 \%$ are familiar with Mac which are consuming less power than windows operating system.

3. AMD and VIA are less energy consuming microprocessors but only 26\% use AMD and 4\% use VIA processor but $42 \%$ are using Intel's microprocessor. More than $50 \%$ people are even not know about their microprocessor then how they can be know the features of these.

4. Google's Blackle search engine is the lowest energy consumption search engine but only $2 \%$ people are familiar with it and use it.

5. According to my survey $57 \%$ people are using printers and from these 57\%, 35\% are using lesser printer but they do not know that lesser printer is the highest energy consumption printer. Inkjet printer consumes very low energy as compare to lesser printer but only $24 \%$ people are using inkjet printers.

6. Todays everyone says that he/she really cares about our environment but they are even not familiar with the terms that are produces harmful impacts on our environment. According to survey only 1 to $9.5 \%$ people are known about these terms like $\mathrm{CO}_{2}$ emission and role of high consumption in polluted environment. There is one interesting fact comes that people are not know about the world environment day and the purpose to celebrate that day. Here a big fact arises that in last 41 years from 1973 to 2013 green computing is not taken as a theme of world environment day. Why?
7. Only 17 to $28 \%$ people are familiar with green computing and its goals.

8. Energy Star program is an international standard for energy efficient products but $69 \%$ people are familiar with it.

9. Only 4 to $10 \%$ people are aware about TCO development its certificate.

10. A computer can be recycle and disposed of safely to save our environment but only $6 \%$ people are familiar with formal disposing and it benefits over environment.

11. Todays various computer manufacturers are taking some initiatives for green computing but only 2 to $16 \%$ people are aware about it.

12. Near about $66 \%$ people are using computer from a long time and more than 5 hours in a day and $41 \%$ have more than one computer but only $26 \%$ users are turn off their computer when they are not in use. Even $90 \%$ people are agree with the term that screen saver saves electricity when computer is idle and $80 \%$ people are using screen saver on their screen but in actual screen saver consumes more electricity when computer is idle.

13. When I told about the green computing and its benefits to these 220 peoples 73 to $87 \%$ people are agree with that government have to take steps towards the awareness of green computing.

14. 65 to $87 \%$ people are agree with the objectives of research.

\section{REFERENCES}

[1] Christian ReimsbachKounatze, "TOWARDS GREEN ICT TRATEGIES: ASSESSING POLICIES AND PROGRAMMES ON ICT AND THE ENVIRONMENT", June 2009.

[2] Fatima Zahra Hanne, "GREEN IT - Why Developing Countries Should Care?", July 2011.

[3] Marguerite Reardon, "Energy - aware Internet Routing Coming soon", August 18, 2009. 
International Journal of Computer Applications Technology and Research

Volume 2- Issue 4, 465 - 473, 2013, ISSN: 2319-8656

[4] AppaGovindasami, Suresh Joseph, "Optimization of Operating Systems towards Green Computing”, Sep-Dec 2012.

[5] RiyazA.Sheikh, Dr. U.A. Lanjewar, "Green Computing Embrace a Secure Future", 2010.

[6] Mydhili K Nair, Dr. V. Gopalakrishna, "Generic Web Services - A step towards Green Computing”, 2009.

[7] UsamaAwan, ShakeelSarwar, Muhammad Amir Raza, "Green Consumer Behaviour and Environmental Sustainability”, September 2011.

[8] Rajguru P.V., Nayak S. K., More D.S., "Solution for Green Computing", June 2010.

[9] JyotiTayade, "Green Computing-Need of Today", April 2012.

[10] RichaSinha, NidhiPurohit, HiteishiDiwanji, "Energy Efficient Dynamic Integration of Thresholds for Migration at Cloud Data Centers", 2012.

[11] K. Mukherjee, G. Sahoo "Green Cloud: An Algorithmic Approach", November 2010. Tom Worthington, "ICT Sustainability: Assessment and Strategies for a Low Carbon Future", 2011.

[12] http://searchdatacenter.techtarget.com/ definition/ greencomputing

[13] http://timesofindia.indiatimes.com/topic/Greencomputing

[14] http://www.greencomputing.co.in/

[15] http://www.wikipedia.org/ 